\title{
Strategies to Prevent Ventilator-associated Lung Injury in Critically III Patients
}

\author{
Alex Joseph ${ }^{1}$, Muhammad Faisal Khan², Rajkumar Rajendram ${ }^{3,4}$ \\ ${ }^{1}$ Department of Anaesthesia and Surgical Intensive Care, Changi General Hospital, Simei, Singapore, ²Department of Anaesthesiology, Aga Khan University, Karachi, \\ Pakistan, ${ }^{3}$ Department of Medicine, King Abdulaziz Medical City, Ministry of National Guard Health Affairs, Riyadh, Saudi Arabia, ${ }^{4}$ Department of Anaesthesia and \\ Intensive Care, Stoke Mandeville Hospital, Aylesbury, UK
}

\section{Abstract}

Life-saving mechanical ventilation (MV) induces or exacerbates a range of pulmonary pathologies, collectively known as ventilator-induced lung injury if there is evidence of direct causation (i.e., in the research laboratory). However, in clinical practice, the term ventilator-associated lung injury (VALI) is more appropriate. While several factors are involved, the main drivers of the pathogenesis are regional overdistention and clinical atelectasis. This understanding has led to search for strategies to attenuate VALI and improve survival. The current approaches focus on reduction of lung stress and strain by limitation of alveolar-plateau pressure and tidal volume. Recent data suggest that control of driving pressure (plateau pressure-positive end-expiratory pressure) and mechanical power applied during ventilation may also be beneficial. More exciting are the various new techniques for MV (e.g., airway pressure release ventilation and neurally adjusted ventilatory assist), emerging alternative modalities for gas exchange (e.g., extracorporeal membrane oxygenation), and novel biological therapies (e.g., anti-inflammatory stem cells) that promise to revolutionize the management of respiratory failure and relegate VALI to the ash heap of history. However, there are currently insufficient data to recommend their use in routine clinical practice.

Keywords: Acute respiratory distress syndrome, ventilator, ventilator-associated lung injury, ventilator-induced lung injury

\section{INTRODUCTION}

Mechanical ventilation (MV) enables oxygenation and clearance of carbon dioxide in critically ill patients who require advanced respiratory support. There is no doubt that MV is life-saving in this context. Unfortunately, the application of MV can induce or exacerbate a range of pulmonary pathologies. If it can be proved that this damage was directly induced by MV alone, then it is ventilator-induced lung injury (VILI). However, outside of the research laboratory, it is virtually impossible to prove direct causation. In clinical practice, it is more appropriate to use the term ventilator-associated lung injury (VALI) ${ }^{[1]}$ Hence, in this review of clinical strategies to prevent this type of lung injury, the term "VILI" will be used when experimental data or pathophysiology are described, but when clinical management is discussed, the term "VALI" will be used instead.

The pathogenesis of VILI is multifactorial and includes clinically apparent side effects of MV such as gross barotrauma (e.g., pneumothorax) and hemodynamic

\begin{tabular}{|l|l|}
\hline \multicolumn{2}{|c|}{ Access this article online } \\
\hline Quick Response Code: & Website: \\
& www.ijrconline.org \\
\cline { 2 - 2 } & \\
\end{tabular}

compromise. ${ }^{[2]}$ However, MV also causes more subtle injuries. ${ }^{[2,3]}$ This more subtle VALI manifests microscopically as increased vascular permeability, inflammatory infiltrates, alveolar hemorrhage, hyaline membrane formation, surfactant dysfunction, interstitial and alveolar edema, and alveolar collapse. ${ }^{[3]}$

At the beginning of this century, the clinical significance of VALI was confirmed by the publication of the Acute Respiratory Distress Syndrome (ARDS) Network's trial of protective ventilation strategies in ARDS. ${ }^{[4]}$ This showed that MV can itself exacerbate pulmonary injury. ${ }^{[4]}$ This landmark trial also demonstrated that ventilation with high tidal volumes $\left(\mathrm{V}_{\mathrm{T}}\right)$ increases mortality in ARDS in comparison to lung protective ventilation. However, VALI also develops in

\section{Address for correspondence: Dr. Rajkumar Rajendram, Department of Anaesthesia and Intensive Care, Stoke Mandeville Hospital, Aylesbury, Buckinghamshire, UK. E-mail: rajkumarrajendram@doctors.org.uk}

This is an open access article distributed under the terms of the Creative Commons Attribution-NonCommercial-ShareAlike 3.0 License, which allows others to remix, tweak, and build upon the work non-commercially, as long as the author is credited and the new creations are licensed under the identical terms.

For reprints contact: reprints@medknow.com

How to cite this article: Joseph A, Khan MF, Rajendram R. Strategies to prevent ventilator-associated lung injury in critically ill patients. Indian $\mathrm{J}$ Respir Care 2018;7:4-13. 
Rajendram, et al:: Prevention of ventilator-associated lung injury

nearly a quarter of patients who receive MV for indications other than ARDS. ${ }^{[5]}$

The clinical presentation of VALI is indistinguishable from progressive ARDS. However, in practice, the management of VALI and ARDS is the same. This review discusses various clinical strategies to prevent VALI. To understand the rationale behind these strategies, it is important to understand the pathogenesis of VALI.

\section{Pathogenesis of Ventilator-associated Lung INJURY}

There are four main mechanisms involved in the pathogenesis of VALI.

1. Barotrauma

2. Volutrauma

3. Atelectrauma

4. Biotrauma.

Several other factors (e.g., body temperature, respiratory rate, and acidemia) are involved in the pathogenesis of VALI but are less important than these.

\section{Barotrauma}

The effects of excessive transpulmonary pressure (TPP; lung stress) were recognized soon after MV was first used. Therapeutic targets were normal blood gases, prevention of dyssynchrony, and avoidance of muscle relaxants. ${ }^{[2-5]}$ Consequently, $\mathrm{V}_{\mathrm{T}}$ and respiratory rates were typically high (e.g., $12 \mathrm{ml} / \mathrm{kg}$ and 20 breaths/min). ${ }^{[2-5]}$ Although most patients "tolerated" the ventilator, gross barotrauma was common. The term "barotrauma" was used to describe the clinically recognizable problems of macroscopic gas escape: pneumothorax, pneumomediastinum, interstitial emphysema, and gas embolism. ${ }^{[3]}$ However, barotrauma also includes more subtle forms of VALI induced by high airway pressures.

\section{Volutrauma}

Ventilation at high (absolute) lung volume (i.e., overdistension; strain) can rupture alveoli, resulting in air leaks and gross barotrauma (e.g., pneumomediastinum). ${ }^{[3]}$ Regional overdistention may occur despite ventilation at low (absolute) lung volumes. This causes more subtle VALI that manifests as pulmonary edema. As regional overdistention of alveoli is far more relevant to VALI than excessive airway pressures, the description of VALI as "barotrauma" can be confusing.

The relevance of pulmonary regional overdistention has been demonstrated in rodents. ${ }^{[6]}$ Hypoxemia and pulmonary edema develop when regional overdistention is induced. Such regional overdistention occurs if MV is applied with extremely high peak airway pressures without positive end-expiratory pressure (PEEP). However, regional overdistention and pulmonary edema can be prevented by the addition of $10 \mathrm{~cm}$ $\mathrm{H}_{2} \mathrm{O}$ PEEP to the same peak airway pressure. Hence, VALI from overdistention is worse at low end-expiratory lung volumes. The mechanics of this relationship remain unclear.
Pulmonary edema also develops in animals ventilated with high $\mathrm{V}_{\mathrm{T}}$, unless abdominal and chest binders are used to limit $\mathrm{V}_{\mathrm{T}}{ }^{[7]}$ Hence, lung distention (i.e., strain) is more damaging than airway pressure (stress). However, stress-induced and strain-induced lung injuries (i.e., barotrauma and volutrauma, respectively) are clearly interrelated.

\section{The relationship between barotrauma and volutrauma}

The pressure required to inflate lungs includes as follows:

1. Pressure needed to overcome airway resistance and inertia (i.e., for gas flow)

2. Pressure needed to overcome pulmonary elastance.

The force distending the lung is not the peak airway pressure, but the TPP (i.e., alveolar pressure-pleural pressure). The lung is deformed above its resting volume (strain) by the difference between the alveolar pressure and the pleural pressure (stress). ${ }^{[8]}$ Thus, barotrauma and volutrauma are two faces of the same VALI. Barotrauma reflects excessive stress while volutrauma reflects excessive strain (overdistention).

The ratio of change in lung volume to the pulmonary volume at rest is used to estimate lung strain. In experimental models, VILI develops when alveoli are exposed to a lung strain $>2$. In healthy animals, this requires delivery of $\mathrm{V}_{\mathrm{T}}$ over $20 \mathrm{ml} / \mathrm{kg}^{.[8,9]}$

However, smaller lung volumes are under more strain during any given change (i.e., inspiration/inflation). At low pulmonary volumes, MV may induce harm by regional amplification of these forces. ${ }^{[10,11]}$ Although alveolar overdistention cannot be measured, reducing inflation pressure should minimize regional overdistention.

Lung volume, TPP, alveolar distention, and VALI are clearly interrelated. Although alveolar overdistention cannot be measured, reducing inflation pressure should minimize regional overdistention. However, there are several limitations to the measurement of pulmonary pressures in routine clinical practice. Pleural pressure can only be estimated in mechanically ventilated patients by the measurement of esophageal pressure. ${ }^{[12]}$ Not only is this measurement complex, difficult, and inaccurate, but because pleural pressure has a gravitational gradient, it also varies throughout the lung.

In contrast, alveolar pressure can be estimated easily. For example, TPP maintains inflation during a period of zero flow (e.g., at end inspiration) in mechanically ventilated patients who are not making any spontaneous respiratory effort. Although the alveolar plateau pressure can easily be measured at end inspiration, calculation of TPP also requires the pleural pressure.

Hence, alveolar-plateau pressure is usually considered in isolation. However, if the patient does not make any effort to breathe, the plateau pressure inflates the chest wall as well as the lungs. If the chest wall is stiff (e.g., due to obesity, large pleural effusions, or ascites), inflation of the chest wall requires significant power and dissipates a large proportion of this pressure. Thus, in a mechanically ventilated patient 
Rajendram, et al:: Prevention of ventilator-associated lung injury

who is not making any spontaneous respiratory effort, a high plateau pressure may not indicate high TPP (i.e., excessive pulmonary stretch). However, during noninvasive ventilation, a distressed patient can generate very large negative pleural pressures. These patients may have very high TPP, despite having low airway pressures. Hence, the focus of prevention of VALI has recently shifted from plateau pressure to driving pressure (i.e., plateau pressure minus PEEP).

\section{Driving pressure}

Amato et al. found that reduction in MV driving pressure was an independent variable (mediator) associated with better survival in their landmark retrospective multilevel "causal" mediation analysis of studies on ARDS. ${ }^{[13]}$ Both allocations to the intervention (i.e., randomization to the lower $\mathrm{V}_{\mathrm{T}}$ group) and lower driving pressure were associated with significantly better survival. However, when analyzed together, only the reduction in driving pressure was independently associated with lower mortality. ${ }^{[13]}$

While clearly thought-provoking, these data cannot be used to recommend that MV should be titrated to target low driving pressures. Even Amato et al. acknowledge that the evidence is indirect and does not establish a direct causal link between a specific driving pressure and outcome. ${ }^{[13]}$ Furthermore, driving pressure is mathematically coupled with $\mathrm{V}_{\mathrm{T}}$ and elastance (driving pressure $=\mathrm{V}_{\mathrm{T}} \times$ elastance) and compliance (driving pressure $=\mathrm{V}_{\mathrm{T}} /$ compliance). Hence, the influence of driving pressure on outcome may be confounded by differences in elastance (severity of the disease) or $\mathrm{V}_{\mathrm{T}}$ (degree of strain) ${ }^{[14,15]}$ Change in elastance or compliance indicates a change in pulmonary mechanics, which is of far greater significance than the choice of a specific value of driving pressure ${ }^{[15]}$ Furthermore, the focus on driving pressure alone ignores the role of PEEP in VALI. A theoretically "safe" driving pressure can still induce VALI if delivered with a PEEP that was set either too high or too low. ${ }^{[15,16]}$

\section{Mechanical power}

A series of laboratory experiments found that application of MV with a pulmonary strain that should be lethal to healthy animals (i.e., above 2 ) only actually resulted in death if delivered at 15 breaths/min. ${ }^{[15]}$ Application of this level of pulmonary strain was not fatal if delivered at rates of 3-6/min. ${ }^{[15]}$ The VILI was more closely related to tidal strain and rate of gas flow than to pulmonary strain at rest (i.e., static strain) ${ }^{[15]}$ Given these data, the cause of VILI could be described by the mechanical power applied during MV; a single physical entity which combines volume, pressures, and flow and respiratory rate. ${ }^{[15]}$

However, the clinical relevance of targeting mechanical power during MV lacks direct evidence of improved outcomes in humans. ${ }^{[15]}$ The same MV power could have very different consequences when applied to damaged lungs rather than healthy lungs. ${ }^{[15]}$ It is therefore important to be able to standardize MV power for an individual patient taking into consideration the size of their lungs, degree of pulmonary parenchymal homogeneity, and regional differences in lung stress or strain. Once these challenges are overcome, it is certainly plausible that a threshold of MV power could direct the delivery of respiratory support.

\section{Tidal atelectasis and atelectrauma}

Ventilation at low (absolute) lung volumes can cause tidal atelectasis and thereby result in "atelectrauma." This is due to frequent collapse and re-opening of alveoli, ${ }^{[16]}$ effects on surfactant, ${ }^{[17]}$ and regional hypoxia. This atelectrauma amplifies the pulmonary damage caused by the initial injury. It manifests as a mosaic-like pattern of collapsed and edematous alveoli interspersed with "normal," open alveoli. This disorganization concentrates stressors at the borders between aerated and atelectatic regions. At these points, the stress and strain on lung parenchyma are up to 4-5 times higher than in other lung regions. ${ }^{[10]}$ Atelectrauma is further increased if ventilation is heterogeneous.

The transition from a normal homogenously ventilated lung into a collection of heterogeneously ventilated alveoli clearly exacerbates VALI. Hence, the delivery of MV should aim to restore or maintain homogeneous gas flow and limit atelectrauma by maintaining adequate lung volumes.

\section{Biotrauma}

Exposure to MV (i.e., regional overdistention) triggers the release of a pantheon of inflammatory mediators within the lungs. These mediators are both pro-inflammatory and anti-inflammatory. Their release results in self-propagating "biotrauma" because these mediators may then damage lung directly, initiate pulmonary fibrosis, or recruit cells such as neutrophils into lung tissue which then release more inflammatory mediators. ${ }^{[18]}$

The physical stress of MV may cause the release of these mediators either:

1. Directly releasing mediators from damaged cells

2. Indirectly by activating cell-signaling pathways (mechanotransduction).

\section{Direct cellular trauma}

Direct damage from the physical stress of MV to the cell disrupts cell walls. Deformation of alveolar cells by mechanical forces results in direct damage and structural changes to cell membrane molecules. This activates downstream messenger systems. Hence, alveolar overinflation induces cellular proliferation and inflammation. As a consequence, cytokines are released into the alveoli, pulmonary circulation, and even the systemic circulation. ${ }^{[18]}$

\section{Mechanotransduction}

Most lung cells produce and release cytokines in response to cyclical stretching and relaxation in vitro ${ }^{[19]}$ In vivo animal models have identified several genes that are either up- or down-regulated when pulmonary tissues are exposed to MV. These include genes that are involved with many complex pathways including immunity and inflammation, metabolism, and gene transcription. ${ }^{[20]}$ However, the processes by which 
Rajendram, et al:: Prevention of ventilator-associated lung injury

these physical forces are detected and transduced into signals that regulate this plethora of intracellular pathways are unclear.

These mediators obviously affect local tissue healing and injury. However, interestingly, these mediators can also initiate or propagate a profound generalized systemic response that causes multiorgan dysfunction or failure.

\section{MODS as a result of VALI}

Although multiorgan dysfunction syndrome (MODS) commonly coexists with ARDS and VALI, it is unclear how these biotraumatic mediators affect distal organs. More importantly, clinical trials of protective ventilation strategies have demonstrated that this intervention reduces serum cytokines, ${ }^{[21]}$ extrapulmonary organ dysfunction, ${ }^{[21]}$ and mortality in patients with ARDS. ${ }^{[4]}$

The systemic release of inflammatory mediators, ${ }^{[21]}$ bacteria, or lipopolysaccharide ${ }^{[22]}$ from the alveoli may occur in the lungs of patients with increased alveolar-capillary permeability. The pathogenesis of ARDS is fundamentally dependent on increased permeability of the alveolar-capillary interface. The permeability of this interface is also increased by volutrauma induced by MV. The systemic release of mediators facilitated by this increase in permeability may precipitate MODS and death.

Hence, VALI reflects the endpoint of volutrauma, barotrauma, atelectrauma, and biotrauma. The primary injury induced by MV (i.e., volutrauma, barotrauma, and atelectrauma) results in the release of inflammatory mediators. This results in both local and systemic effects which can have profound consequences. The recognition of the significance of VALI transformed the approach to $\mathrm{MV}$ in routine clinical practice.

\section{Prevention}

The focus on VALI has distracted clinicians from the management of many other stressors which cause alveolar overdistention and cyclical atelectasis. For example, marked increases in minute ventilation also result in alveolar overdistention. Increasing minute ventilation by injecting sodium salicylate into the cisterna magna of sheep breathing spontaneously induces changes similar to VILI and hypoxemia. ${ }^{[23]}$ This was prevented by controlling ventilation to limit lung stretch.

Thus, the focus of clinical strategies to prevent worsening of lung injury in patients requiring MV should be on the reduction of alveolar overdistention and cyclical atelectasis. The reduction of this primary insult should reduce secondary biotrauma.

\section{Clinical Practice}

The current strategies to prevent VALI include lung protective ventilation strategies, adjunctive strategies (e.g., prone positioning, nitric oxide), and extracorporeal gas exchange (to avoid invasive MV) or a combination of these. These strategies are described below.
Several studies have evaluated the effect of various approaches to limit alveolar distention and cyclic atelectasis in patients receiving MV for ARDS. ${ }^{[24]}$

Various approaches to MV are used to minimize pulmonary damage in patients with ARDS:

1. Delivering low $\mathrm{V}_{\mathrm{T}}$ and while maintaining a low plateau pressure to prevent overdistention. This is often referred to as "lung protective ventilation"

2. High PEEP to reduce cyclical atelectasis

3. Recruitment maneuvers

4. Open lung approach to MV

5. Airway pressure release ventilation (APRV)

6. High-frequency oscillatory ventilation (HFOV).

These interventions have varying degrees of data from human studies on their use in patients with ARDS. For example, ARDS Network ventilation which combines low $\mathrm{V}_{\mathrm{T}}$, limitation of plateau pressure under $30 \mathrm{~cm} \mathrm{H}_{2} \mathrm{O}$, and titration of PEEP to $\mathrm{FiO}_{2}$ improves mortality such that only 11 patients had to be treated to prevent one death (i.e., the number needed to treat [NNT] was 11). ${ }^{[4]}$

Yet, few trials have examined these interventions in patients who do not have ARDS. However, while the data from clinical trials help intensivists make difficult decisions, the literature will never fully address the complexity of many clinical situations. Hence, because these strategies are considered safe, they are often also used in patients who require MV but do not have ARDS.

It is important to highlight that the ventilation strategies listed above deliberately excludes references to driving pressure and mechanical power. This is because driving pressure mathematically correlates with $\mathrm{V}_{\mathrm{T}}$, elastance, compliance, and plateau pressure. ${ }^{[13-15]}$ Hence, when plateau pressure, $V_{T}$, and PEEP are set for a protective ventilation strategy, limitation of driving pressure per se does not confer any additional benefit. ${ }^{[14,15]}$ Similarly, while limitation of mechanical power applied during ventilation may also be beneficial, there is currently insufficient evidence to advocate this.

\section{Preventing alveolar overdistention with low tidal volume mechanical ventilation and limitation of plateau pressure Low tidal volume ventilation}

Lung regions that are dependent, i.e., lower in terms of their gravitational position (e.g., lower lobes in the supine patient), are more likely to collapse. Hence, in patients receiving MV, dependent lung is often less well aerated than the nondependent lung regions. Hence, a smaller volume is available for ventilation. ${ }^{[25]}$

Alveolar overdistention is limited by delivering small $\mathrm{V}_{\mathrm{T}}$, maintaining a low plateau pressure, and using pressure-limited ventilation. The advantages of this MV strategy in ARDS were confirmed by the landmark randomized controlled trial conducted by the ARDS Network investigators who compared a high $\mathrm{V}_{\mathrm{T}}\left(12 \mathrm{ml} / \mathrm{kg}\right.$ predicted body weight) with a low $\mathrm{V}_{\mathrm{T}} \mathrm{MV}$ strategy $(6 \mathrm{ml} / \mathrm{kg}) .{ }^{[4]}$ The low $\mathrm{V}_{\mathrm{T}} \mathrm{MV}$ strategy reduced mortality 
by $9 \%(12 \mathrm{ml} / \mathrm{kg}, 39.8 \% ; 6 \mathrm{ml} / \mathrm{kg}, 31.0 \%)$. This is referred to as low $\mathrm{V}_{\mathrm{T}}$ ventilation.

The optimal $\mathrm{V}_{\mathrm{T}}$ for patients without ARDS who require MV is not known. However, some studies suggest that MV using low $\mathrm{V}_{\mathrm{T}}$ may also benefit patients without ARDS. ${ }^{[26]}$ In one randomized clinical trial (RCT) of intraoperative MV which compared $6-8 \mathrm{ml} / \mathrm{kg}$ ideal body weight (IBW) (i.e., low $\mathrm{V}_{\mathrm{T}}$ ) with $10-12 \mathrm{ml} / \mathrm{kg}$ IBW (i.e., high $\mathrm{V}_{\mathrm{T}}$ ), patients who received 6-8 $\mathrm{ml} / \mathrm{kg}$ IBW had fewer pulmonary complications (e.g., pneumonia), extrapulmonary complications (e.g., sepsis), and reintubations than those receiving higher $\mathrm{V}_{\mathrm{T}}{ }^{\left[{ }^{[2,24]}\right.}$ There was no difference in the development of ARDS or death. However, the study was not sufficiently powered to detect this.

One meta-analysis (15 RCT and 5 observational studies) reported that patients receiving $\mathrm{MV}$ with $\mathrm{V}_{\mathrm{T}}$ around $6 \mathrm{ml} / \mathrm{kg}$ IBW had less risk of VALI (risk ratio [RR] 0.33, 95\% confidence interval [CI] 0.23-0.47) and death (RR 0.64, $95 \%$ CI $0.46-0.89)$ than those ventilated with higher $\mathrm{V}_{\mathrm{T}}{ }^{\left[{ }^{[27]}\right.}$ Another meta-analysis (7 studies) found that fewer patients on low $\mathrm{V}_{\mathrm{T}}$ ventilation $(\leq 7 \mathrm{ml} / \mathrm{kg}$ ) progressed to ARDS, developed pneumonia, or died than patients receiving higher $\mathrm{V}_{\mathrm{T}}(>7 \mathrm{ml} / \mathrm{kg}){ }^{[28]}$ However, both analyses were limited by the methodological flaws of the RCT and the inclusion of observational data.

However, as regional hyperinflation can still occur with $\mathrm{V}_{\mathrm{T}}$ around $6 \mathrm{ml} / \mathrm{kg} \mathrm{IBW}$, it may be better to use lower $\mathrm{V}_{\mathrm{T}}$, ${ }^{[6]}$ despite plateau pressures already below $30 \mathrm{~cm} \mathrm{H}_{2} \mathrm{O}^{[7]}$ Low $\mathrm{V}_{\mathrm{T}}$ ventilation often results in hypercapnea. ${ }^{[22]}$ In the absence of raised intracranial pressure or right heart failure, $\mathrm{PaCO}_{2}$ up to $70 \mathrm{mmHg}$ with $\mathrm{pH}>7.2$ are safe $^{[29]}$ and may even be beneficial. The rationale for permissive hypercapnea includes the beneficial effects of acidosis on tissue oxygenation (i.e., right shift in hemoglobin oxygen dissociation, increase in cardiac output, and potentiation of hypoxic pulmonary vasoconstriction). ${ }^{[29]}$ However, unfortunately, low $\mathrm{V}_{\mathrm{T}}$ ventilation is sometimes difficult to achieve without increased sedation or neuromuscular blockade, which have other risks. ${ }^{[30]}$

Hence, large RCT is required to extend the use of low $\mathrm{V}_{\mathrm{T}}$ ventilation to all patients receiving MV. Until such data are available, based upon extrapolation from the limited data that are currently available, a $\mathrm{V}_{\mathrm{T}}$ of $6-8 \mathrm{ml} / \mathrm{kg} \mathrm{IBW}$ is reasonable to use as a starting point for $\mathrm{MV}$ in patients with and without ARDS.

\section{Plateau pressure limitation}

Several studies have investigated plateau pressure in patients with ARDS receiving MV. Although no absolute preferred plateau pressure has been identified, mortality is improved when plateau pressures during $\mathrm{MV}$ are maintained below $30 \mathrm{~cm} \mathrm{H}_{2} \mathrm{O}$. ${ }^{[4]}$ One observational study of 30 patients with ARDS receiving MV suggested that if the amount of nonaerated lung is large, it may be better to maintain plateau pressure under $28 \mathrm{~cm} \mathrm{H}_{2} \mathrm{O}^{[31]}$

Although there are no studies in patients without ARDS, these data suggest that, in the context of VALI, plateau pressure is not a threshold variable but rather a continuous variable. This may be because lower plateau airway pressures are associated with less alveolar distension. Hence, lower the plateau pressure, the better. Pressure-limited ventilation (e.g., pressure control) reduces alveolar overdistention by ensuring that airway pressure does not rise above the set limit. ${ }^{[32]}$

However, limiting plateau pressure to $30 \mathrm{~cm} \mathrm{H}_{2} \mathrm{O}$ may be too low in some cases. If the chest wall is very stiff (e.g., because of large pleural effusions or ascites), overdistention of the alveoli may not occur even at plateau pressures well above $30 \mathrm{~cm} \mathrm{H}_{2} \mathrm{O}$. If a patient with a stiff chest wall is hypoxemic, the use of higher plateau pressures should be considered. However, there is no literature to guide ventilator settings in these situations. In these situations, intensivists must apply physiological principles alongside the data available from trials.

\section{Methods to Prevent Cyclic Atelectasis}

\section{The use of positive end-expiratory pressure to prevent cyclic atelectasis}

The use of sufficient PEEP to prevent de-recruitment at end-expiration should reduce atelectrauma. Pulmonary edema and end-expiratory alveolar collapse are involved in the pathogenesis of several causes of respiratory failure. The use of PEEP splints alveoli open and reduces cyclic atelectasis. However, higher PEEP may have adverse effects (e.g., reduced venous return and pulmonary overdistention).

Higher levels of PEEP are protective in animal models of ARDS, but human data are inconsistent. ${ }^{[3]]}$ The failure of these in studies in humans to demonstrate beneficial effects from the application of PEEP may be because MV was not tailored to the specific characteristics of a patient's lungs. Most of these clinical trials used a fixed protocol to select PEEP. Most PEEP titration protocols used airway pressure and gas exchange parameters to select PEEP but do not take pleural pressure or lung recruitability into consideration. The failure to consider the characteristics of a patient's lungs when selecting PEEP may result in selection of an inappropriate level of PEEP. Underapplication or overapplication of PEEP can both predispose to VALI.

A recent meta-analysis considered these conflicts in the management of ARDS. ${ }^{[32]}$ This reported that an absolute reduction of $5 \%$ in the mortality of moderate and severe ARDS $\left(\mathrm{PaO}_{2}: \mathrm{FiO}_{2}\right.$ under $\left.200 \mathrm{mmHg}\right)$ was associated with higher PEEP. ${ }^{[31]}$ However, an optimal PEEP has not been established.

\section{The myth of "optimal” positive end-expiratory pressure}

The aim of the application of PEEP is to improve oxygenation and facilitate open-lung ventilation (i.e., minimize cyclical atelectasis). However, there is no such thing as an "optimal" PEEP, so there is no optimal method to determine this mythical value of PEEP. However, at some point, MV parameters must be set. Hence, the PEEP setting is said to be optimal when: 
Rajendram, et al:: Prevention of ventilator-associated lung injury

1. Oxygenation is best

2. There is minimal end-expiratory atelectasis (i.e., maximal end-expiratory recruitment)

3. There is minimal end-inspiratory overdistention.

Several methods are used to select PEEP in routine clinical practice [Table 1]. Some aim to optimize oxygenation as their primary goal, while others prioritize lung protection.

\section{Role of esophageal pressure monitoring in setting positive end-expiratory pressure}

When setting MV, TPP (alveolar pressure-pleural pressure) should be considered. However, pleural pressure cannot be measured directly. Esophageal pressure is a surrogate for pleural pressure and can be measured by esophageal balloon manometry. However, interpretation is difficult because of artifacts from cardiac contraction, gravitational pleural pressure gradient, and distortion and contraction of the esophagus. ${ }^{[12]}$ Despite these limitations, use of esophageal manometry has been studied in a pilot study involving patients with ARDS. ${ }^{[12]}$

In this study, PEEP was adjusted to keep TPP under $10 \mathrm{~cm} \mathrm{H}_{2} \mathrm{O}$ at end-expiration. End-inspiratory TPP was limited to $25 \mathrm{~cm} \mathrm{H}_{2} \mathrm{O}$. Oxygenation improved. There was also a nonsignificant trend toward lower 28-day mortality. However, this small pilot study was not adequately powered to detect a mortality benefit. While tantalizing, a larger trial confirming that this strategy improves clinically important outcomes is needed before the use of TPP to guide MV can be recommended in routine clinical practice.

Independent of TPP, the beneficial effects of high levels PEEP around $15 \mathrm{~cm} \mathrm{H}_{2} \mathrm{O}$ appear to outweigh the potentially detrimental effects due to alveolar strain, particularly if there is recruitable lung volume. ${ }^{[4]}$

Clinicians often set PEEP above the lower inflection point of the patient's MV pressure--volume curve. This should splint

\footnotetext{
Table 1: Methods used to set positive end-expiratory pressure

Set arbitrarily high PEEP (15-20 $\mathrm{cm} \mathrm{H}_{2} \mathrm{O}$; CT studies support use of a PEEP of around $16 \mathrm{~cm} \mathrm{H}_{2} \mathrm{O}$ )

Set PEEP according to oxygen requirement (e.g., use the ARDSNet $\mathrm{PEEP} / \mathrm{FiO}_{2}$ titration protocol)

Set PEEP to avoid cyclic atelectasis (above the lower inflection point of the pressure-volume curve)

Set PEEP during a staircase recruitment maneuver

To provide the highest static compliance

To maintain best oxygenation (i.e., best $\mathrm{SpO}_{2}$ )

To maintain least $\mathrm{V}_{\mathrm{T}}$ dead space (i.e., lowest arterial minus end-tidal $\mathrm{CO}_{2}$ gradient)

To maintain lowest intrapulmonary shunt (i.e., highest $\mathrm{SvO}_{2}$ )

Set PEEP to provide the greatest amount of aerated lung

Using electrical impedance tomography

Using sequential CT scans to see lung volume at end-expiration Set PEEP, so transpulmonary pressure is $0-10$ at end-expiration (requires esophageal manometry)

PEEP: Positive end-expiratory pressure, ARDS: Acute respiratory distress syndrome, CT: Computed tomography
}

alveoli open and reduces cyclical atelectasis. However, this strategy alone does not improve clinically relevant outcomes and the appropriate amount of PEEP to apply is difficult to determine because to plot the MV pressure-volume curve accurately usually requires neuromuscular blockade.

\section{Recruitment maneuvers}

Atelectasis occurs as a result of de-recruitment which may itself reflect low $\mathrm{V}_{\mathrm{T}}$ ventilation, inadequate PEEP, or absorption atelectasis after administration of high inspired concentrations of oxygen. Recruitment maneuvers involve delivery of a high airway pressure (i.e., $>35 \mathrm{~cm} \mathrm{H}_{2} 0$ ) for at least $40-60 \mathrm{~s}$. These maneuvers aim to reinflate atelectatic lung and minimize ventilation heterogeneity.

Recruitment maneuvers should reduce VALI and have been studied. ${ }^{[33,34]}$ However, their role in clinical practice remains uncertain. This is primarily because there is no evidence that lung recruitment improves outcomes. Furthermore, there are valid concerns regarding the potential complications of sustained high airway pressures (e.g., cardiovascular compromise and air leaks). ${ }^{[34]}$

\section{Open lung ventilation}

Open lung ventilation combines delivery of small $\mathrm{V}_{\mathrm{T}}$ with the application of PEEP above the low inflection point on the MV pressure--volume curve and recruitment maneuvers. Several studies have suggested improved oxygenation, reduced need for rescue therapies and more ventilator-free days using this approach.${ }^{[35]}$ However, a recent international multicenter RCT of 1013 patients with moderate-to-severe ARDS reported that 28-day all-cause mortality was increased by a high PEEP open lung MV strategy (55.3\%) in comparison to a low PEEP ARDSNet MV strategy (49.3\%). ${ }^{[35]}$ Hence, while some subgroups may benefit from open lung MV with recruitment maneuvers, the evidence of benefit is weak, and there a clear risk of harm in comparison to ARDS Network MV.

\section{Airway pressure release ventilation}

APRV is pressure-controlled, intermittent mandatory MV with an extreme inverse ratio that allows spontaneous breathing throughout the respiratory cycle. This mode of MV is based on open lung MV. A high continuous-positive airway pressure (CPAP) is delivered for a prolonged period (e.g., 4.5-6 s) to recruit lung and is only released briefly (e.g., $0.5-0.8 \mathrm{~s}$ ) to zero PEEP to allow ventilation without de-recruitment. ${ }^{[36]}$ As the prevention of VALI focuses on "opening the lung and keeping it open," this is a conceptually ideal mode of ventilation. ${ }^{[36]}$

Ventilator manufacturers have caused significant confusion about MV by developing several different terminologies for similar modes. This is particularly relevant for APRV which has not been clearly or consistently defined. Indeed, a significantly underinvestigated aspect of VALI is the influence of the brand and model of ventilator. Each ventilator has a unique specification. The resistances built into the MV gas flow circuit, the responses to spontaneous ventilation, and the 
Rajendram, et al.: Prevention of ventilator-associated lung injury

software which differ between brands and models of ventilator all influence the delivery of each breath. Further research is therefore urgently required to evaluate the effect of the model of ventilator on VALI.

More problematic than the different terminology that ventilator manufacturer's use for similar modes of ventilation is the wide variation in their delivery of these modes. As a result, the MV settings used by researchers and clinicians vary significantly. One APRV variant, P-APRV recruits alveoli homogeneously during a $90 \%$ CPAP phase that inflates the lung. ${ }^{[3]}$ This is followed by a brief release phase personalized to the patient's lung mechanics. This results in an almost static yet ventilated lung. Cyclical atelectasis is minimized and thereby dynamic tissue strain is reduced. ${ }^{[36]}$

A meta-analysis reported that the incidence of ARDS was reduced by a factor of 10 and mortality was reduced by a factor of three in trauma patients treated with this mode of MV (P-APRV) in comparison to trauma patients with similar injuries treated with standard ventilation. ${ }^{[37]}$ Of all the currently available literature, only this study ${ }^{[37]}$ has reported the precise P-APRV settings that were used. Despite showing promise, all of the human data on P-APRV are retrospective, so a large RCT demonstrating improvement in clinical outcomes is necessary before any form of APRV can be recommended in routine practice.

\section{High-frequency oscillatory ventilation}

HFOV delivers tiny $\mathrm{V}_{\mathrm{T}}$ (less $\mathrm{V}_{\mathrm{T}}$ than the anatomical dead space) at frequencies up to $15 / \mathrm{s}$. A meta-analysis (eight trials involving 419 adults with ARDS) ${ }^{[38]}$ reported that mortality was significantly lower in those treated with HFOV than those treated with standard MV. However, in two recent large multicenter trials (OSCAR and OSCILLATE), use of HFOV did not benefit patients with ARDS ${ }^{[39,40]}$ Hence, HFOV should not be used in patients with ARDS. Furthermore, it has not been studied in patients without ARDS.

\section{Physiological strategies to minimize ventilator-associated lung injury \\ Neurally adjusted ventilatory assist}

Inspiratory diaphragmatic electrical activity (EAdi) reflects feedback loops travelling via the vagus nerve that collate data from pulmonary mechanoreceptors (which detect stretch) and chemoreceptors. ${ }^{[41]}$ In patients receiving MV EAdi increases if the $V_{T}$ delivered by MV is less than the patient's respiratory requirement. The EAdi decreases if the $\mathrm{V}_{\mathrm{T}}$ delivered is more than the patient's respiratory requirement.

Neurally adjusted ventilatory assist (NAVA) delivers MV pressure support in proportion to EAdi. A specific nasogastric tube measures EAdi and the intensivist sets the proportion on the ventilator. When respiratory demand is satisfied, $\mathrm{V}_{\mathrm{T}}$ is stable despite increases in the support proportion. ${ }^{[42]}$ This synchronized breath-by-breath support in proportion to respiratory demand is particularly beneficial if work of breathing is increased and/or respiratory muscles are weak.
On NAVA, innate reflexes limit $\mathrm{V}_{\mathrm{T}}$ if lungs are overstretched. This allows patients to "regulate" their delivered $\mathrm{V}_{\mathrm{T}}$. Hence, NAVA can prevent overdistention and limit VALI, unload the muscles of respiration while improving tolerance of the ventilator. ${ }^{[3,44]}$ To the degree that self-regulating ventilatory defense mechanisms can prevent lung overinflation, NAVA may improve patient outcomes by tailoring delivery of MV breath by breath. ${ }^{[45]}$

This mode of MV was studied in rabbits with ARDS induced by administration of hydrochloric acid. The rabbits were randomized to one of the three groups. They received NAVA or volume-controlled MV with either high $(15 \mathrm{ml} / \mathrm{kg})$ or conventional $(6 \mathrm{ml} / \mathrm{kg}) \mathrm{V}_{\mathrm{T}}{ }^{[45]}$ This study demonstrated that NAVA and standard low $\mathrm{V}_{\mathrm{T}}$ ventilation provide similar lung protection. However, whether the protective feedback mechanism observed in rabbits is relevant to severe respiratory failure in humans is unclear. Hence, these data require confirmation by randomized controlled clinical trials in humans before use in routine practice can be recommended.

\section{Mechanical ventilation in the prone position}

Oxygenation increases in about $70 \%$ of hypoxemic patients with ARDS when MV is delivered in a prone position. ${ }^{[4]}$ Reasons for this include increased end-expiratory lung volume, reduced compression of the lower lobes by the heart and improved regional ventilation. ${ }^{[46]}$ The net result of these changes is better ventilation-perfusion matching. The delivery of MV in the prone position should also limit VALI by decreasing pulmonary heterogeneity. ${ }^{[47,48]}$

It is important to note that proning is not without risk. Patients who are "proned" have more complications, including pressure ulcers, endotracheal tube obstruction, and chest tube dislodgment. However, these complications are potentially preventable. Hence, despite these adverse events, prone positioning has been shown to significantly reduce absolute mortality in patients with severe ARDS. ${ }^{[49]}$ In a recent trial of proning in patients with moderate and severe ARDS, 28-day mortality was significantly higher $(32.8 \%)$ in those treated supine than in those who were proned $(16.0 \%) .{ }^{[50]}$ The absolute reduction in mortality with proning was $16 \%$, so the NNT to prevent one death was remarkably only 6.2. Prone positioning is therefore an important intervention that should be strongly considered in patients with refractory hypoxia.

\section{Partial or total extracorporeal support}

An innovative approach is to avoid MV using extracorporeal membrane oxygenation (ECMO) or carbon dioxide removal. ${ }^{[51]}$ If $\mathrm{MV}$ is combined with partial extracorporeal support, the MV required to provide adequate oxygenation and carbon dioxide removal is reduced by that provided by the extracorporeal circuit. ${ }^{[52]}$ This hybrid approach has fewer complications than full ECMO and reduces VALI as $\mathrm{V}_{\mathrm{T}}$ can be reduced.

Some (predominantly observational) data support this management strategy ${ }^{[3,54]}$ However, further randomized data are necessary to determine which patients require extracorporeal support and indeed when and which technique to use. 
Rajendram, et al.: Prevention of ventilator-associated lung injury

\section{Sedation, neuromuscular blocking agents, and control of fever}

The main purpose of $\mathrm{MV}$ is to allow gas exchange (i.e., oxygenation and clearance of $\mathrm{CO}_{2}$ ). A nonspecific approach to limit VALI is to reduce patients' metabolic demands (e.g., by sedation, neuromuscular blockade [NMB], and prevention of fever) and thereby the required minute ventilation for gas exchange.

Ventilator synchrony and metabolic demands are improved by NMB. This allows reduction of $\mathrm{V}_{\mathrm{T}}$ and pressure. In an animal model of lung injury, spontaneous breathing improved lung recruitment if the lung injury was mild but was associated with more cyclic atelectasis/atelectrauma and tidal hyperinflation than NMB. ${ }^{[55,56]}$

A multicenter, placebo-controlled, RCT reported that 90-day mortality in patients with moderate and severe ARDS was reduced after NMB for 48 h. ${ }^{[57]}$ Interestingly, the benefit on mortality was only apparent approximately 16 days after the initiation of NMB. Serum cytokine levels are lower in patients receiving NMB ${ }^{[58]}$ Hence, the delayed mortality benefit seen with NMB could reflect reduced biotrauma-induced multiorgan failure. ${ }^{[57]}$ Importantly, there was no increase in critical care myopathy with NMB therapy.

\section{Anti-inflammatory agents and stem cells}

Anti-inflammatory agents ${ }^{[58]}$ and mesenchymal stem cells ${ }^{[59]}$ have been studied in VILI in laboratory studies in animals. The main potential benefit of these agents in the prevention of VILI, over their role in other inflammatory diseases, is that treatment could be initiated before the patient is exposed to the causative factor (i.e., before administration of MV). However, no reports of the use of any of these treatments in humans are currently available.

\section{CONCLUSION}

Improved understanding of VILI and VALI has led to the development of protective MV strategies to reduce VALI and improve patient outcomes. The current focus on prevention of VALI has shifted to consideration of driving pressure and mechanical power. However, the relevance of these variables over $\mathrm{V}_{\mathrm{T}}$ and plateau pressure lacks direct proof. There are several emerging modalities (e.g., ECMO, NAVA, P-APRV, and NMB) and novel approaches (e.g., anti-inflammatory stem cells) that promise to revolutionize the management of respiratory failure and relegate VALI to the ash heap of history. However, there is currently insufficient data to recommend their use in routine practice. Indeed, the recurring theme of this review is that further randomized controlled trials are required. However, while the data from clinical trials certainly help intensivists make difficult decisions, the literature can never fully addresses the conflicting priorities of many clinical scenarios.

\section{Financial support and sponsorship}

Nil.

\section{Conflicts of interest}

There are no conflicts of interest.

\section{REFERENCES}

1. International consensus conferences in intensive care medicine: Ventilator-associated lung injury in ARDS. This official conference report was cosponsored by the American thoracic society, the European Society of Intensive Care Medicine, and the Societé de Réanimation de Langue Française, and was approved by the ATS board of directors, July 1999. Am J Respir Crit Care Med 1999;160:2118-24.

2. Nash G, Blennerhassett J, Pontoppidan H. Pulmonary lesions associated with oxygen therapy and artificial ventilation. Laval Med 1968;39:59-64.

3. Avignon PD, Hedenstrom G, Hedman C. Pulmonary complications in respirator patients. Acta Med Scand Suppl 1956;316:86-90.

4. Acute Respiratory Distress Syndrome Network, Brower RG, Matthay MA, Morris A, Schoenfeld D, Thompson BT, et al. Ventilation with lower tidal volumes as compared with traditional tidal volumes for acute lung injury and the acute respiratory distress syndrome. N Engl J Med 2000;342:1301-8.

5. Gajic O, Dara SI, Mendez JL, Adesanya AO, Festic E, Caples SM, et al. Ventilator-associated lung injury in patients without acute lung injury at the onset of mechanical ventilation. Crit Care Med 2004;32:1817-24.

6. Webb HH, Tierney DF. Experimental pulmonary edema due to intermittent positive pressure ventilation with high inflation pressures. Protection by positive end-expiratory pressure. Am Rev Respir Dis 1974;110:556-65.

7. Dreyfuss D, Soler P, Basset G, Saumon G. High inflation pressure pulmonary edema. Respective effects of high airway pressure, high tidal volume, and positive end-expiratory pressure. Am Rev Respir Dis 1988;137:1159-64.

8. Chiumello D, Carlesso E, Cadringher P, Caironi P, Valenza F, Polli $\mathrm{F}$, et al. Lung stress and strain during mechanical ventilation for acute respiratory distress syndrome. Am J Respir Crit Care Med 2008;178:346-55.

9. Protti A, Cressoni M, Santini A, Langer T, Mietto C, Febres D, et al. Lung stress and strain during mechanical ventilation: Any safe threshold? Am J Respir Crit Care Med 2011;183:1354-62.

10. Mead J, Takishima T, Leith D. Stress distribution in lungs: A model of pulmonary elasticity. J Appl Physiol 1970;28:596-608.

11. Muscedere JG, Mullen JB, Gan K, Slutsky AS. Tidal ventilation at low airway pressures can augment lung injury. Am J Respir Crit Care Med 1994;149:1327-34.

12. Zin WA, Milic-Emili J. Esophageal pressure measurement. In: Hamid Q, Shannon J, Martin J, editors. Physiologic Basis of Respiratory Disease. Hamilton, ON, Canada: Bc Decker; 2005. p. 639-47.

13. Amato MB, Meade MO, Slutsky AS, Brochard L, Costa EL, Schoenfeld DA, et al. Driving pressure and survival in the acute respiratory distress syndrome. N Engl J Med 2015;372:747-55.

14. Guérin C, Papazian L, Reignier J, Ayzac L, Loundou A, Forel JM, et al. Effect of driving pressure on mortality in ARDS patients during lung protective mechanical ventilation in two randomized controlled trials. Crit Care 2016;20:384.

15. Tonetti T, Vasques F, Rapetti F, Maiolo G, Collino F, Romitti F, et al. Driving pressure and mechanical power: New targets for VILI prevention. Ann Transl Med 2017;5:286.

16. BilekAM, Dee KC, GaverDP $3^{\text {rd }}$. Mechanisms of surface-tension-induced epithelial cell damage in a model of pulmonary airway reopening. J Appl Physiol (1985) 2003;94:770-83.

17. Albert RK. The role of ventilation-induced surfactant dysfunction and atelectasis in causing acute respiratory distress syndrome. Am J Respir Crit Care Med 2012;185:702-8.

18. Tremblay LN, Slutsky AS. Ventilator-induced injury: From barotrauma to biotrauma. Proc Assoc Am Physicians 1998;110:482-8.

19. Vlahakis NE, Schroeder MA, Limper AH, Hubmayr RD. Stretch induces cytokine release by alveolar epithelial cells in vitro. Am J Physiol 1999;277:L167-73.

20. Nonas SA, Moreno-Vinasco L, Ma SF, Jacobson JR, Desai AA, 
Rajendram, et al.: Prevention of ventilator-associated lung injury

Dudek SM, et al. Use of consomic rats for genomic insights into ventilator-associated lung injury. Am J Physiol Lung Cell Mol Physiol 2007;293:L292-302.

21. Ranieri VM, Suter PM, Tortorella C, De Tullio R, Dayer JM, Brienza A, et al. Effect of mechanical ventilation on inflammatory mediators in patients with acute respiratory distress syndrome: A randomized controlled trial. JAMA 1999;282:54-61.

22. Murphy DB, Cregg N, Tremblay L, Engelberts D, Laffey JG, Slutsky AS, et al. Adverse ventilatory strategy causes pulmonary-to-systemic translocation of endotoxin. Am J Respir Crit Care Med 2000;162:27-33.

23. Mascheroni D, Kolobow T, Fumagalli R, Moretti MP, Chen V, Buckhold D, et al. Acute respiratory failure following pharmacologically induced hyperventilation: An experimental animal study. Intensive Care Med 1988;15:8-14.

24. Petrucci N, De Feo C. Lung protective ventilation strategy for the acute respiratory distress syndrome. Cochrane Database Syst Rev 2013;2:CD003844.

25. Gattinoni L, Pesenti A. The concept of "baby lung". Intensive Care Med 2005;31:776-84.

26. Ladha K, Vidal Melo MF, McLean DJ, Wanderer JP, Grabitz SD, Kurth $\mathrm{T}$, et al. Intraoperative protective mechanical ventilation and risk of postoperative respiratory complications: Hospital based registry study. BMJ 2015;351:h3646.

27. Serpa Neto A, Cardoso SO, Manetta JA, Pereira VG, Espósito DC, Pasqualucci Mde O, et al. Association between use of lung-protective ventilation with lower tidal volumes and clinical outcomes among patients without acute respiratory distress syndrome: A meta-analysis. JAMA 2012;308:1651-9.

28. Neto AS, Simonis FD, Barbas CS, Biehl M, Determann RM, Elmer J, et al. Lung-protective ventilation with low tidal volumes and the occurrence of pulmonary complications in patients without acute respiratory distress syndrome: A Systematic review and individual patient data analysis. Crit Care Med 2015;43:2155-63.

29. Hickling KG, Henderson SJ, Jackson R. Low mortality associated with low volume pressure limited ventilation with permissive hypercapnia in severe adult respiratory distress syndrome. Intensive Care Med 1990;16:372-7.

30. Hraiech S, Yoshida T, Papazian L. Balancing neuromuscular blockade versus preserved muscle activity. Curr Opin Crit Care 2015;21:26-33.

31. Terragni PP, Rosboch G, Tealdi A, Corno E, Menaldo E, Davini O, et al. Tidal hyperinflation during low tidal volume ventilation in acute respiratory distress syndrome. Am J Respir Crit Care Med 2007;175:160-6.

32. Briel M, Meade M, Mercat A, Brower RG, Talmor D, Walter SD, et al. Higher vs. lower positive end-expiratory pressure in patients with acute lung injury and acute respiratory distress syndrome: Systematic review and meta-analysis. JAMA 2010;303:865-73.

33. Talmor D, Sarge T, Malhotra A, O'Donnell CR, Ritz R, Lisbon A, et al. Mechanical ventilation guided by esophageal pressure in acute lung injury. N Engl J Med 2008;359:2095-104.

34. Brower RG, Morris A, MacIntyre N, Matthay MA, Hayden D, Thompson $\mathrm{T}$, et al. Effects of recruitment maneuvers in patients with acute lung injury and acute respiratory distress syndrome ventilated with high positive end-expiratory pressure. Crit Care Med 2003;31:2592-7. [Erratum, Crit Care Med 2004;32:907].

35. Writing Group for the Alveolar Recruitment for Acute Respiratory Distress Syndrome Trial (ART) Investigators, Cavalcanti AB, Suzumura ÉA, Laranjeira LN, Paisani DM, Damiani LP, et al. Effect of lung recruitment and titrated positive end-expiratory pressure (PEEP) vs. low PEEP on mortality in patients with acute respiratory distress syndrome: A Randomized clinical trial. JAMA 2017;318:1335-45.

36. Jain SV, Kollisch-Singule M, Sadowitz B, Dombert L, Satalin J, Andrews $\mathrm{P}$, et al. The 30-year evolution of airway pressure release ventilation (APRV). Intensive Care Med Exp 2016;4:11.

37. Andrews PL, Shiber JR, Jaruga-Killeen E, Roy S, Sadowitz B, O'Toole RV, et al. Early application of airway pressure release ventilation may reduce mortality in high-risk trauma patients: A systematic review of observational trauma ARDS literature. J Trauma Acute Care Surg 2013;75:635-41.
38. Sud S, Sud M, Friedrich JO, Meade MO, Ferguson ND, Wunsch H, et al. High frequency oscillation in patients with acute lung injury and acute respiratory distress syndrome (ARDS): Systematic review and meta-analysis. BMJ 2010;340:c2327.

39. Ferguson ND, Cook DJ, Guyatt GH, Mehta S, Hand L, Austin P, et al. High-frequency oscillation in early acute respiratory distress syndrome. N Engl J Med 2013;368:795-805.

40. Young D, Lamb SE, Shah S, MacKenzie I, Tunnicliffe W, Lall R, et al. High-frequency oscillation for acute respiratory distress syndrome N Engl J Med 2013;368:806-13.

41. Allo JC, Beck JC, Brander L, Brunet F, Slutsky AS, Sinderby CA, et al. Influence of neurally adjusted ventilatory assist and positive end-expiratory pressure on breathing pattern in rabbits with acute lung injury. Crit Care Med 2006;34:2997-3004.

42. Sinderby C, Navalesi P, Beck J, Skrobik Y, Comtois N, Friberg S, et al. Neural control of mechanical ventilation in respiratory failure. Nat Med 1999;5:1433-6.

43. Piquilloud L, Vignaux L, Bialais E, Roeseler J, Sottiaux T, Laterre PF, et al. Neurally adjusted ventilatory assist improves patient-ventilator interaction. Intensive Care Med 2011;37:263-71.

44. Mauri T, Bellani G, Grasselli G, Confalonieri A, Rona R, Patroniti N, et al. Patient-ventilator interaction in ARDS patients with extremely low compliance undergoing ECMO: A novel approach based on diaphragm electrical activity. Intensive Care Med 2013;39:282-91.

45. Brander L, Sinderby C, Lecomte F, Leong-Poi H, Bell D, Beck J, et al. Neurally adjusted ventilatory assist decreases ventilator-induced lung injury and non-pulmonary organ dysfunction in rabbits with acute lung injury. Intensive Care Med 2009;35:1979-89.

46. Piedalue F, Albert RK. Prone positioning in acute respiratory distress syndrome. Respir Care Clin N Am 2003;9:495-509.

47. Broccard A, Shapiro RS, Schmitz LL, Adams AB, Nahum A, Marini JJ, et al. Prone positioning attenuates and redistributes ventilator-induced lung injury in dogs. Crit Care Med 2000;28:295-303.

48. Valenza F, Guglielmi M, Maffioletti M, Tedesco C, Maccagni P, Fossali T, et al. Prone position delays the progression of ventilator-induced lung injury in rats: Does lung strain distribution play a role? Crit Care Med 2005;33:361-7.

49. Sud S, Friedrich JO, Taccone P, Polli F, Adhikari NK, Latini R, et al. Prone ventilation reduces mortality in patients with acute respiratory failure and severe hypoxemia: Systematic review and meta-analysis. Intensive Care Med 2010;36:585-99.

50. Guérin C, Reignier J, Richard JC, Beuret P, Gacouin A, Boulain T, et al. Prone positioning in severe acute respiratory distress syndrome. N Engl J Med 2013;368:2159-68.

51. Brodie D, Bacchetta M. Extracorporeal membrane oxygenation for ARDS in adults. N Engl J Med 2011;365:1905-14.

52. Gattinoni L, Kolobow T, Agostoni A, Damia G, Pelizzola A, Rossi GP, et al. Clinical application of low frequency positive pressure ventilation with extracorporeal CO2 removal (LFPPV-ECCO2R) in treatment of adult respiratory distress syndrome (ARDS). Int J Artif Organs $1979 ; 2: 282-3$

53. Terragni PP, Del Sorbo L, Mascia L, Urbino R, Martin EL, Birocco A, et al. Tidal volume lower than $6 \mathrm{ml} / \mathrm{kg}$ enhances lung protection: Role of extracorporeal carbon dioxide removal. Anesthesiology 2009;111:826-35.

54. Bein T, Weber-Carstens S, Goldmann A, Müller T, Staudinger T, Brederlau J, et al. Lower tidal volume strategy $(\approx 3 \mathrm{ml} / \mathrm{kg})$ combined with extracorporeal $\mathrm{CO} 2$ removal versus 'conventional' protective ventilation $(6 \mathrm{ml} / \mathrm{kg})$ in severe ARDS: The prospective randomized xtravent-study. Intensive Care Med 2013;39:847-56.

55. Forel JM, Roch A, Marin V, Michelet P, Demory D, Blache JL, et al. Neuromuscular blocking agents decrease inflammatory response in patients presenting with acute respiratory distress syndrome. Crit Care Med 2006;34:2749-57.

56. Yoshida T, Uchiyama A, Matsuura N, Mashimo T, Fujino Y. The comparison of spontaneous breathing and muscle paralysis in two different severities of experimental lung injury. Crit Care Med 2013;41:536-45

57. Papazian L, Forel JM, Gacouin A, Penot-Ragon C, Perrin G, Loundou A, et al. Neuromuscular blockers in early acute respiratory distress 
Rajendram, et al.: Prevention of ventilator-associated lung injury

syndrome. N Engl J Med 2010;363:1107-16.

58. Curley GF, Hayes M, Ansari B, Shaw G, Ryan A, Barry F, et al. Mesenchymal stem cells enhance recovery and repair following ventilator-induced lung injury in the rat. Thorax 2012;67:496-501.
59. Needham DM, Colantuoni E, Mendez-Tellez PA, Dinglas VD, Sevransky JE, Dennison Himmelfarb CR, et al. Lung protective mechanical ventilation and two year survival in patients with acute lung injury: Prospective cohort study. BMJ 2012;344:e2124. 